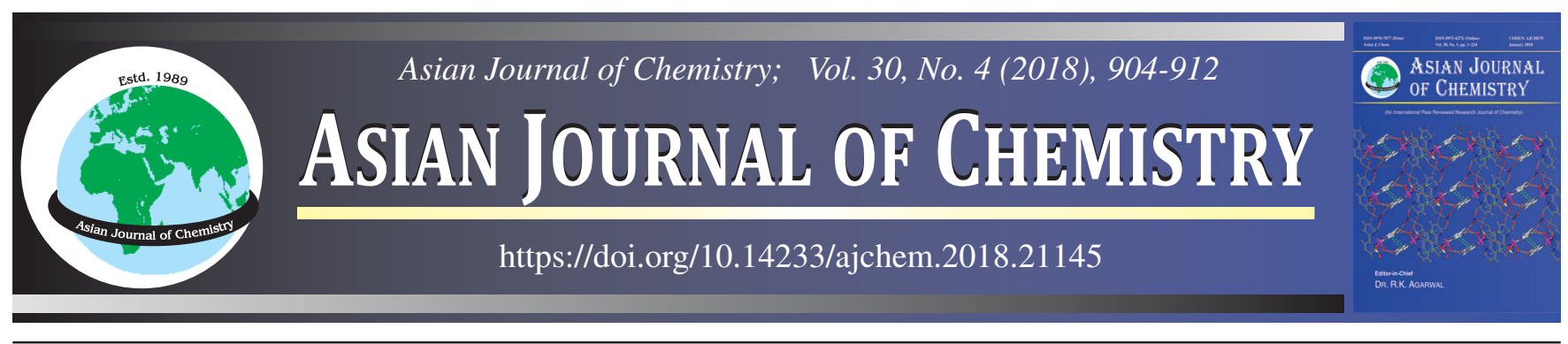

\title{
in silico Quest Guided by Physico-Chemical Descriptors of Bedaquiline for New Scaffolds with Potential Inhibitory Capacity against Homology Model of Mycobacterium $F_{1} F_{0}$ ATP Synthase
}

\author{
Rama Krishna Munnaluri and Vijullatha Manga*
}

Molecular Modeling and Medicinal Chemistry Group, Department of Chemistry, University College of Science, Osmania University, Hyderabad500007 , India

*Corresponding author: E-mail: vijjulathamanga@gmail.com

Received: 22 November 2017;

Accepted: 5 January 2018;

Published online: 28 February 2018;

AJC-18809

\begin{abstract}
As the first US FDA approved drug for treating pulmonary multi drug resistant tuberculosis (MDR-TB) in the last 40 years, bedaquiline $\left(\right.$ TMC207, Sirturo $^{\mathrm{TM}}$ ) stands out as cynosure in the circles of synthetic chemists exploring new therapeutics against tuberculosis. The remarkable efficacy of bedaquiline in treating tuberuculosis lies in its ability to target the energy metabolism that affects both replicating as well as dormant forms of M. tuberculosis (MTB). Despite its promising antitubercular profile, bedaquiline raises serious concern with its string of side effects and emergence of resistant strains, warrants a quest for better substitutes. In the present work, we employed in silico methods like homology modeling and virtual screening to zero in on molecules that exhibit high affinity at the binding site of bedaquiline.
\end{abstract}

Keywords: Bedaquiline, Pubchem database, MTB $\mathrm{F}_{1} \mathrm{~F}_{0}$ ATP synthase, Homology modeling, Virtual screening, Molecular docking.

\section{INTRODUCTION}

Tuberculosis (TB) till date remains one of the most dreaded infectious diseases, registering an alarming death count nearing 1.8 million every year worldwide. Latest estimates of World Health Organization (WHO) adds more to this disturbing tale, approximately 10.4 million people across the World are infected with tuberculosis in 2016 [1]. The growing number of infected patients can also be related to increased incidence of HIV as tuberculosis remains one of the most common co-infection and also main cause of mortality in HIV patients [2]. What further complicates the treatment of tuberculosis is emergence of multidrug-resistant tuberculosis (MDR-TB), extensively drug resistant tuberculosis (XDR-TB) and most virulent totally drug resistant tuberculosis (TDR-TB) [3,4]. The current regimen of antituberculosis drugs target different biological pathways important for the survival of the Mycobacterium tuberculosis (MTB) and quest for new pathways that can be targeted is on full swing [5]. With most of the drugs in use are rendered ineffective or less effective due to emergence of drug resistant strains, developing new strategies and finding new targets is a pressing need to mitigate the risk of drug resistance [6,7]. One such pathway that has garnered lot of attention lately is energy metabolism in MTB and this obviously is credited to the US FDA approval for bedaquiline, reported to inhibit $F_{1} F_{0}$ ATP synthase [8,9]. Replicating or non-replicating tuberculi need to maintain threshold levels of ATP for their survival. This probably is the moot point for the incredible success of bedaquiline, known to kill both active as well latent forms of MTB by inter-fering in ATP synthesis and effecting a rapid depletion of intra-cellular ATP levels $[10,11]$. Bedaquiline is highly selective towards MTB $\mathrm{F}_{1} \mathrm{~F}_{0}$ ATP synthase and has minimal interaction with human ATP synthase [12].

In the present work, our interest is restricted to $\mathrm{F}_{0}$, specifically, the inferace of subunit-a and rotor, comprising subunitc, which has been experimentally validated to be the binding site of bedaquiline (Fig. 1). Bedaquiline, despite its superior antituberculosis profile comes with a host of side effects that include arthralgia, nausea, hemoptysis, chestpain and headache $[13,14]$. Also to quell the risk of emergence of bedaquiline resistant strains, it is imperative to explore molecules that can act as bedaquiline substitutes with fewer side effects.

\section{EXPERIMENTAL}

Homology modeling of MTB ac protein complex: A high resolution $\mathrm{X}$-ray diffraction structure of rotor complex in M. phlei with $\mathrm{c}_{9}$ configuration (PDB ID: $4 \mathrm{~V} 1 \mathrm{G}$; resolution: $1.55 \AA$ ) and the same protein with co-crystallized bedaquiline (PDB ID: 4V1F; resolution: $1.7 \AA$ ) (http://www.rcsb.org/pdb/) has been solved by Preiss et al. [15]. The structure is invaluable in understanding the binding mode of bedaquiline and $M$. phlei 

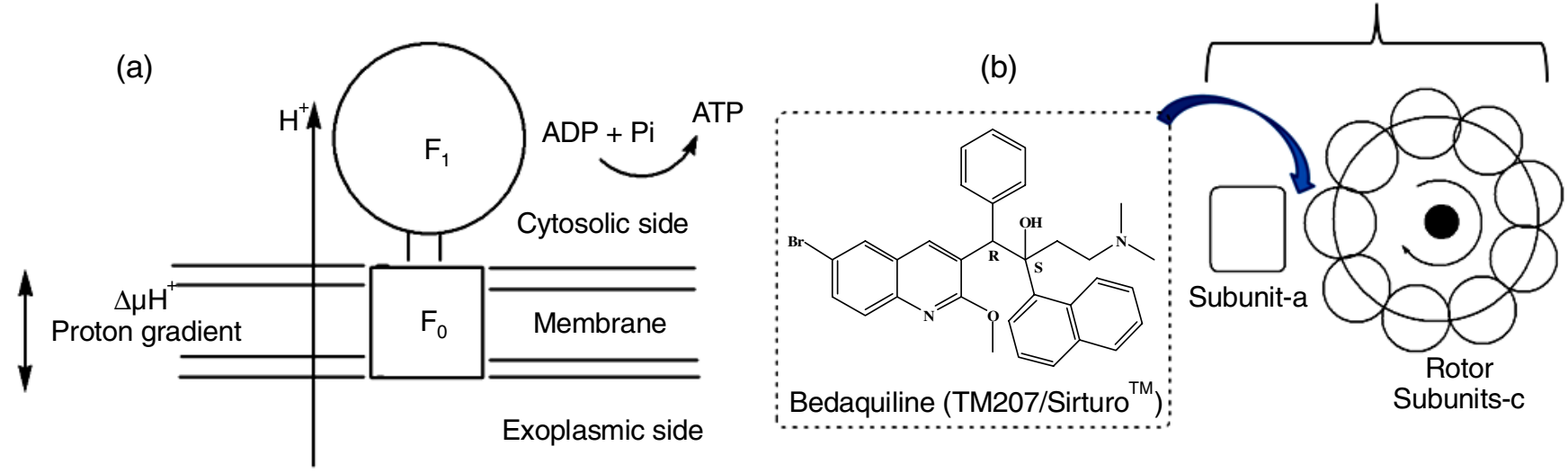

Fig. 1. (a) Skeletal view of $\mathrm{F}_{1} \mathrm{~F}_{0}$ ATP synthase (b) Binding site of bedaquiline at the interface of subunit-a and subunit-c (rotor)

shares an impressive $90 \%$ sequence identity with pathogenic bacterium's rotor sequence. The minimum inhibitory concentration (MIC) values of bedaquiline against MTB $(0.06 \mu \mathrm{g} /$ $\mathrm{mL})$ and $M$. phlei $(0.05 \mu \mathrm{g} / \mathrm{mL})$ are very close and imply high resemblance in binding mode of the drug with the protein. One short coming in solved X-ray structures of M. phlei rotor ring $(4 \mathrm{~V} 1 \mathrm{G}$ or $4 \mathrm{~V} 1 \mathrm{~F})$ is absence of subunit-a, which forms the interface with the rotor $c_{9}$ and it is at this very interface bedaquiline is reported to bind. The molecular docking studies will give meaningful results if the native environment of the protein as in vivo conditions can be replicated. To achieve this we planned to build a homology model of pathogenic MTB rotor along with the subunit-a, so as to generate the interface which is known to host the binding site of bedaquiline. Previous workers performed molecular docking studies employing homology model of ac $\mathrm{ac}_{12}$ protein complex using $E$. coli $\mathrm{F}_{1} \mathrm{~F}_{0}$ ATP synthase subunit-a and rotor complex (PDB ID: 1C17) as template that share relatively low sequence similarity (Table-1) [16-19]. One advantage with $1 \mathrm{C} 17$ template, despite low sequence identity with query sequence is presence of both subunit-a and entire rotor with $\mathrm{c}_{12}$ configuration.

TABLE-1

TEMPLATE SEQUENCE IDENTITY FOR SUB UNITS a AND c OF MTB

\begin{tabular}{cccc}
\hline \multirow{2}{*}{ Template PDB code } & \multirow{2}{*}{ Organism } & \multicolumn{2}{c}{ Sequence identity to } \\
\cline { 3 - 4 } & & Subunit-a & Subunit-c \\
\hline 1C17 $\left(\mathrm{F}_{1} \mathrm{~F}_{0} \mathrm{ac}_{12}\right.$ complex $)$ & E. coli & $38 \%$ & $52 \%$ \\
& & (Chain: $\mathrm{M})$ & $($ Chain: $\mathrm{A})$ \\
4V1G $\left(\right.$ rotor- $\left.\mathrm{c}_{9}\right)$ & M. phlei & - & $90 \%$ \\
\hline
\end{tabular}

Sequence identity calculations were performed using BLAST online server [Ref. 20].

In order to build a homology model that is proximal to the native protein, we planned to build a multi template based composite model that contains $\mathrm{C}_{9}$ rotor from template $4 \mathrm{~V} 1 \mathrm{G}$ with high sequence identity and subunit-a from template $1 \mathrm{C} 17$ that shared low sequence identity with the target protein. To achieve this objective we build homology model of protein ensemble $\mathrm{ac}_{9}$ as a hybrid of two homology models both built with query sequences of MTB H37Rv on SWISS MODEL homology modeling server [21-23]. Model-1 was generated using template $4 \mathrm{~V} 1 \mathrm{G}$ that contained only subunit-c and model2 was obtained using template $1 \mathrm{C} 17$ that contained subunit-a along with c-12 rotor. A composite model that contained $\mathrm{c}_{9}$ rotor and subunit-a, was generated by aligning the interface of $\mathrm{ac}_{12}$ of model- 2 to $\mathrm{c}_{9}$ of model 1 by using protein structure alignment option available in maestro panel of Schrödinger suite (Fig. 2). The alignment score was 0.2 on a scale of 0 to 1 where smaller value corresponds to greater alignment and value of 0.2 indicates marginal deviation which is expected owing to difference in templates used. The update coordinates option in maestro panel was used and background $\mathrm{c}_{12}$ rotor of homology model 2 was deleted to generate a protein complex now comprising of subunit-a from model-2 (chain $\mathrm{M}$ ) and rotor $\mathrm{c}_{9}$ (Chains A to I) from model-1 (Fig. 2). The modeled protein ensemble was saved as a separate entry in project table of maestro module.

Model validation: Homology model validation was carried out using RAMPAGE server (Fig. 3) [24], ProSA web (Fig. 4) [25] and QMEANBrane online server (Fig. 5) (specific for validating membrane spanning proteins) [26]. The model showed reasonably good compliance with the accepted standards and indicates a reliable homology model of $\mathrm{ac}_{9}$ complex.

Protein preparation: The homology model built is not suitable for immediate use in molecular docking studies and need further processing. This job is accomplished by using protein preparation wizard module in Schrödinger suite [27]. Protein preparation wizard fixes issues with regard to the structure and also allows minimization of protein.

Grid generation: The grid generation is supposedly most important step in molecular docking studies and accuracy of the docking results are invariably dependent on this crucial step. A fair degree of knowledge from biochemical assays and bedaquiline bound PDB structure of M. phlei (PDB ID: 4V1F) indicate the binding site to be proximal to Glu-61 (Fig. 6). An initial rotational scan was performed on Arg-186 and other interface residues to select the conformations of these interface residues that do not interfere with binding of bedaquiline [28]. Generation of a grid around Glu-61 was carried out using default settings of the Glide module of Schrödinger suite.

Ligand preparation of bedaquiline and its stereosisomers: A 2D structure of bedaquiline was first built using maestro panel of Schrödinger suite. The structure was then submitted 
Model: $c_{9}$ rotor

Template: 4V1G

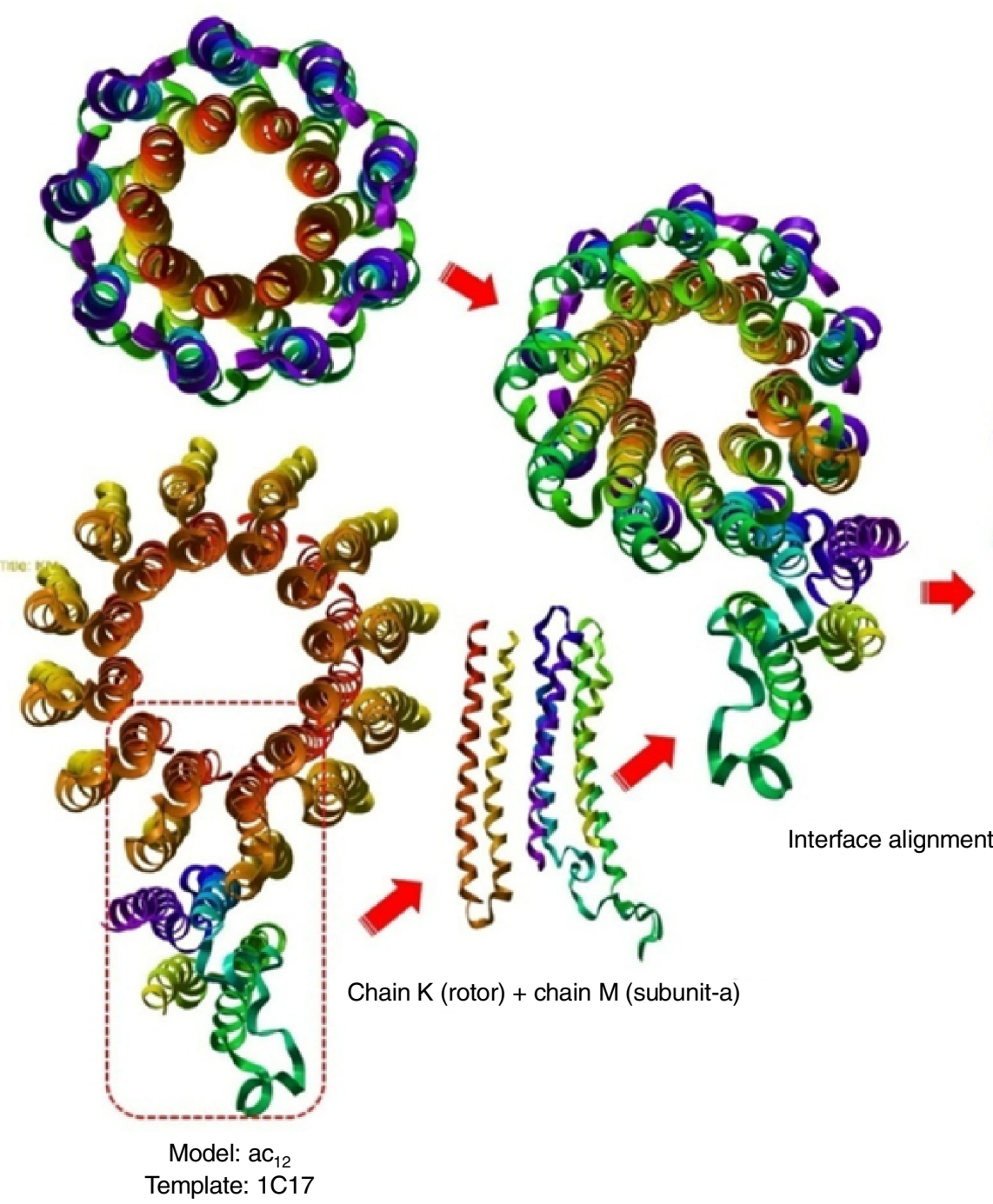

Fig. 2. Graphical representation of scheme employed in generating model ac ${ }_{9}$ protein complex

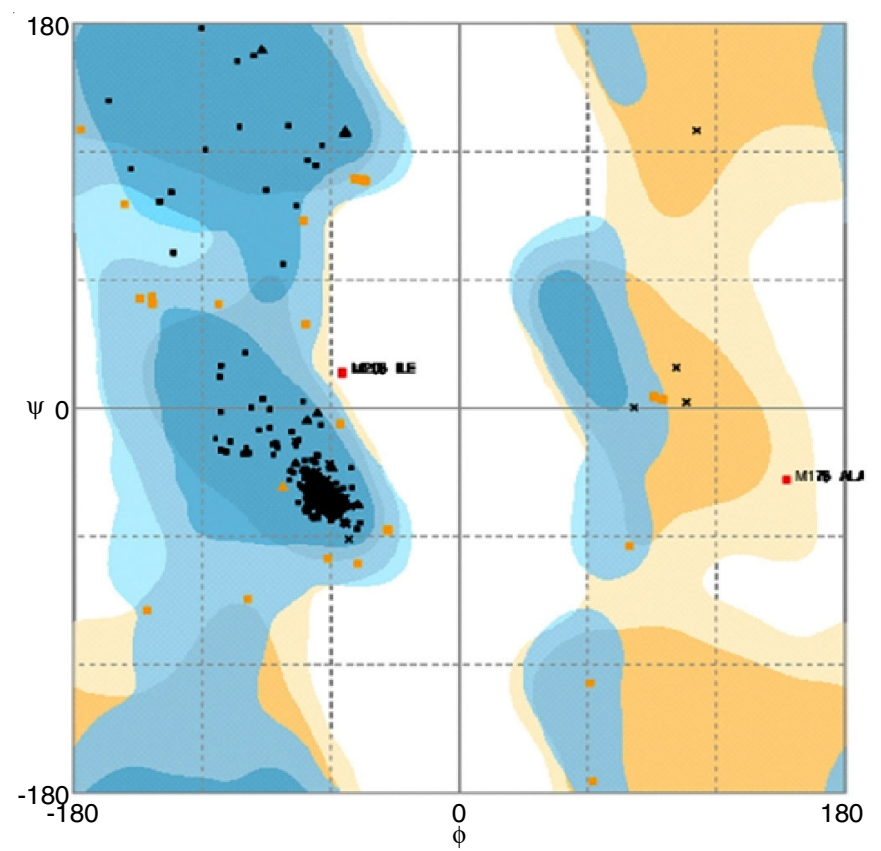

Total number of residues $\quad: 843$

Number of residues in favoured region : $797(94.5 \%)$

Number of residues in allowed region : $44(5.2 \%)$

Number of residues in outlier region : $2(0.2 \%)$

- General/pre-pro/proline favoured

$\times$ Glycine favoured

General/pre-pro/proline allowed

Glycine allowed

Fig. 3. Ramachandran plot for the modeled protein 

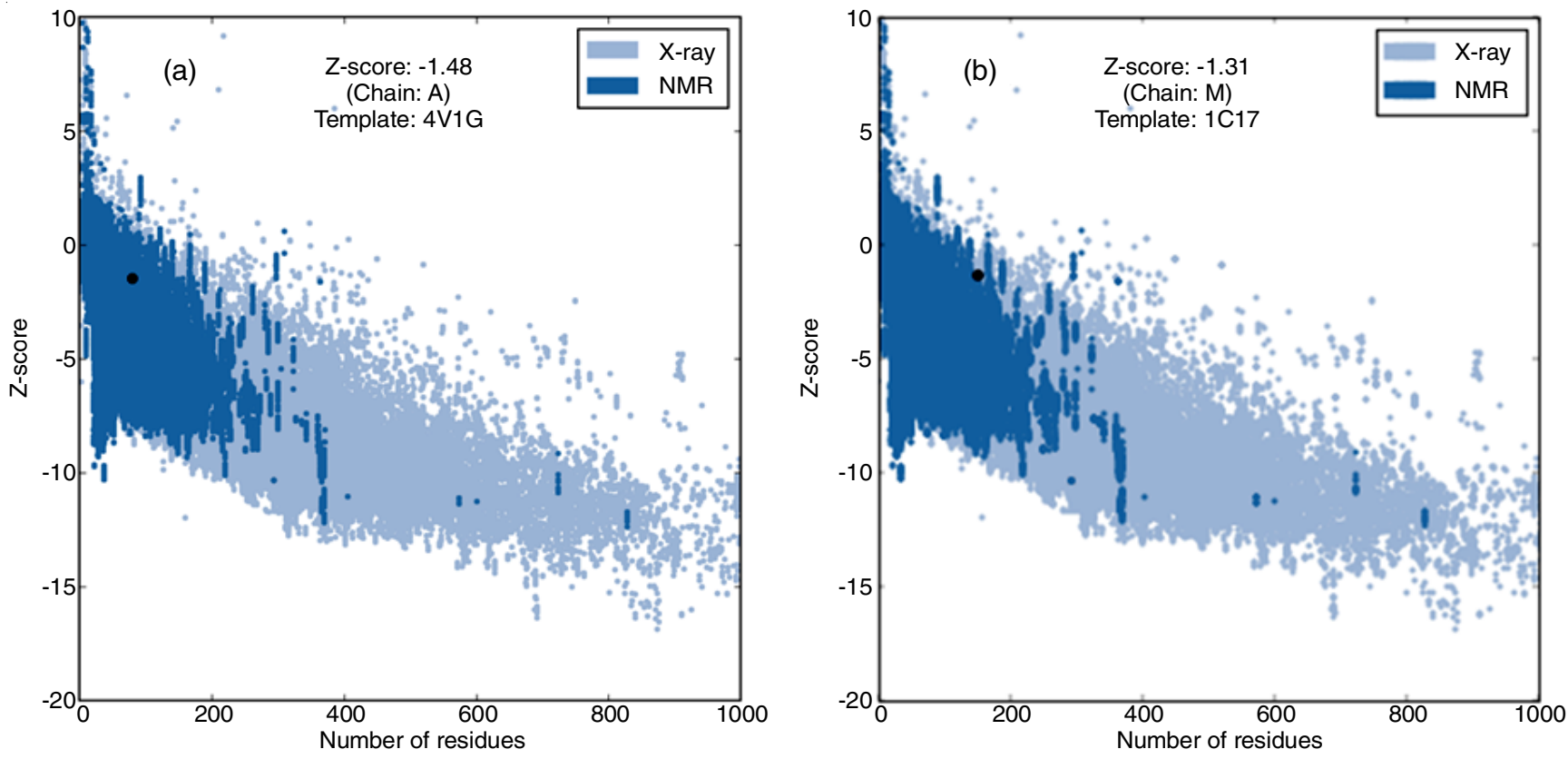

Fig. 4. ProSA plots for the modeled protein for chains A (rotor) and M (subunit-a)

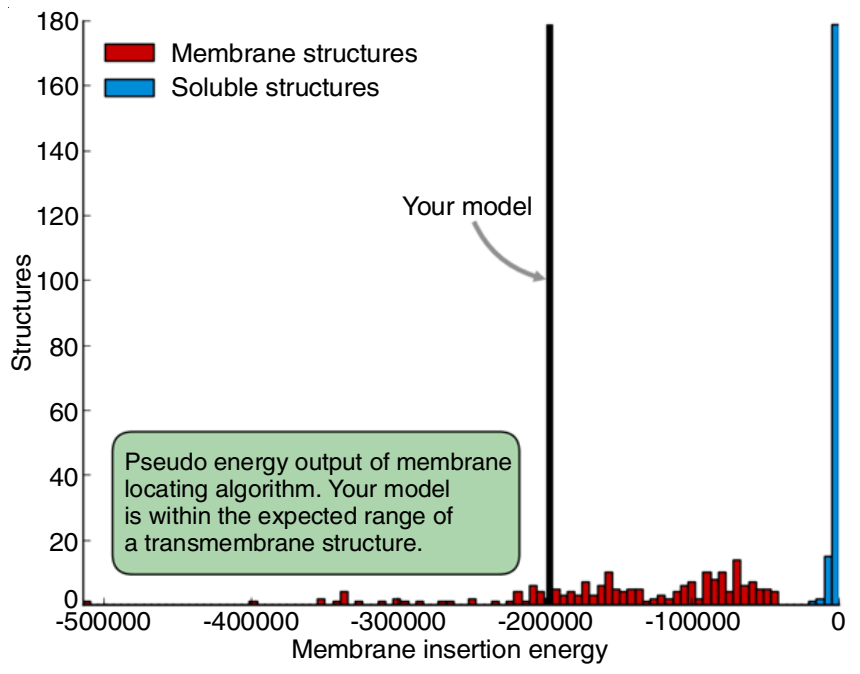

to ligprep module to obtain different 3D structures of stereoisomers, conformers and ionization states for the input structure. Out of these stereoisomers, lowest energy conformers of 4 stereoisomers i.e. $(\mathrm{R}, \mathrm{S})$ [Bedaquiline], $(\mathrm{S}, \mathrm{R}),(\mathrm{S}, \mathrm{S})$ and $(\mathrm{S}, \mathrm{S})$ were selected for further molecular docking studies.

Molecular docking of bedaquiline and its stereoisomers: Our objective in the present work is to screen molecules with high binding affinity to the $\mathrm{MTB}_{1} \mathrm{~F}_{0}$ ATP synthase ac $\mathrm{c}_{9}$ protein complex and this would warrant a bench mark to screen actives. For this, first we docked all the four low energy stereoisomers including bedaquiline into the grid by using extra precision (XP) mode available in Glide module. This would allow us to not just arrive at the docking cut-off to screen actives but as well compare the binding affinities of different stereoisomers of bedaquiline at the binding site.

Fig. 5. QMEANBrane plot of membrane insertion energy for the model ac,

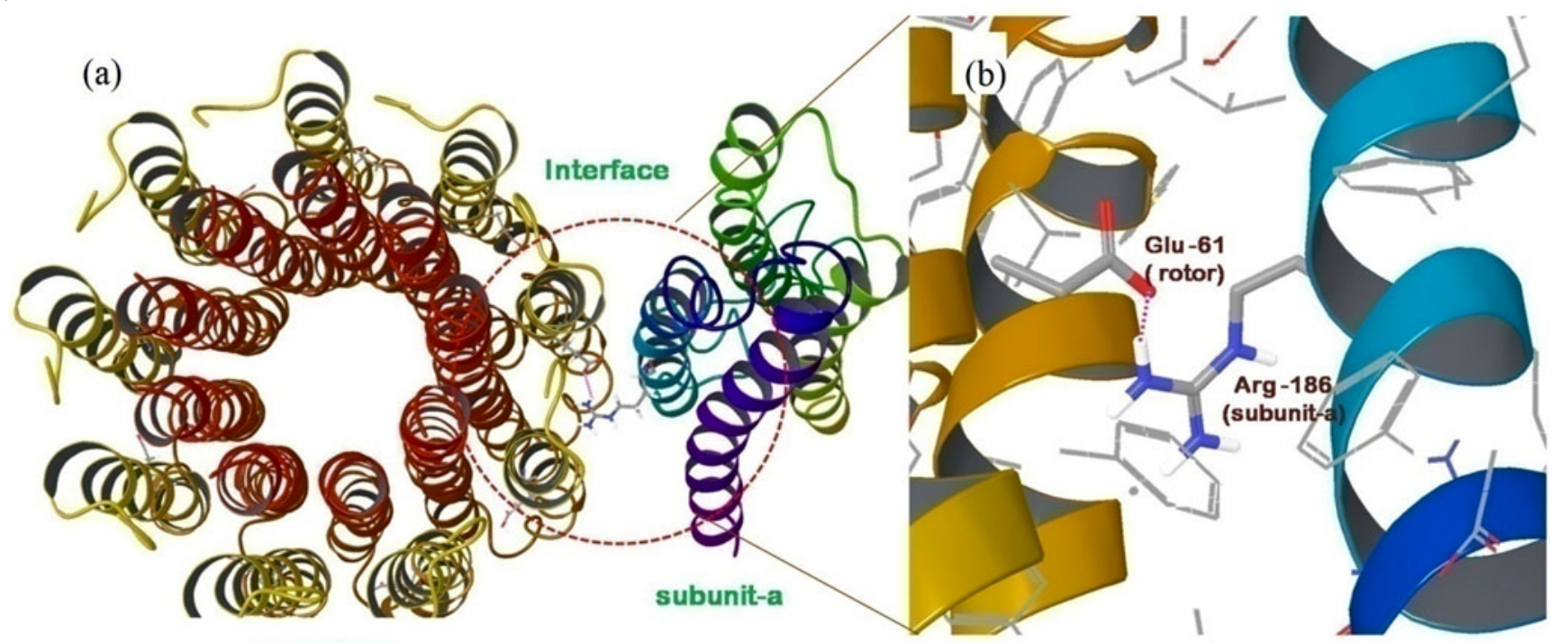

C9ROTOR

Fig. 6. (a) Interface of subunit-c (rotor) and subunit-a (b) The crucial interaction between Glu-61 (subunit-c of rotor) and Arg-186 (subunit-a) 


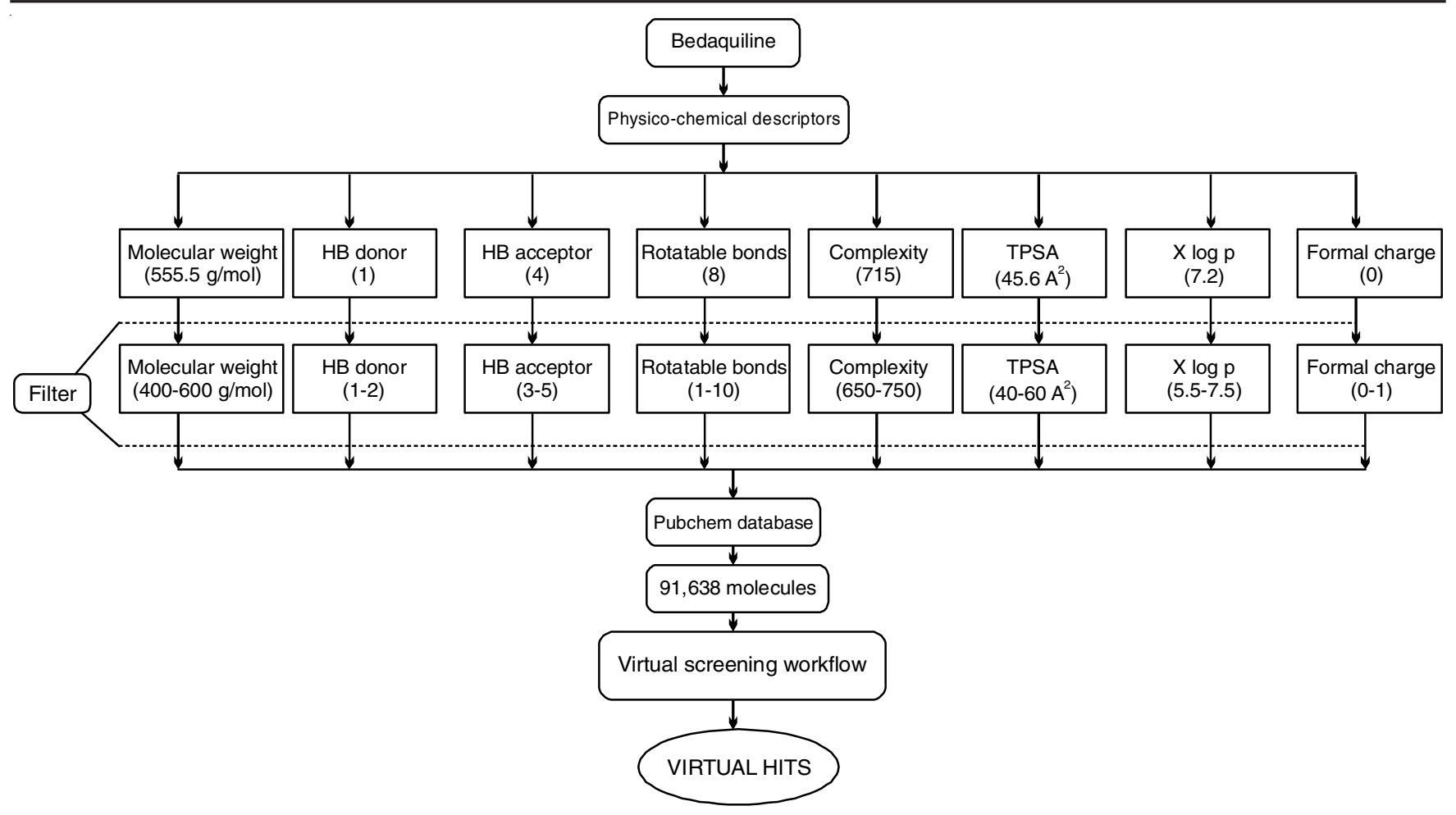

Fig. 7. Schematic showing the criterion employed for extracting a focused library from pubchem database

Preparation of focused library: Pubchem database is a voluminous collection of more than 79 millions compounds with unique structures tagged with their bioactivity information and is maintained by National Center for Biotechnology Information (NCBI) (website info: https://pubchem.ncbi.nlm.nih.gov/) [29]. Freely accessible, web user interface allows selective download of the molecules as per ones specification of physicochemical or biological data. It is a well established fact that biological activity of any compound can be related it to its structural framework and we applied this tenet to prepare a focused library of compounds which share common physical or structural features with bedaquiline [30,31]. In the present context bedaquiline is seen not just as a single molecule but as a representative of wide range of diarylquinoline (DARQ) class of compounds that commonly share a significant antituberculosis profile. The selection criterion for the focused library preparation has been outlined in Fig. 7.

A library of 91,638 molecules was downloaded in sdf format from the PubChem website. Before further use, all these molecules in the library were prepared by using ligprep module and then advanced into virtual screening protocol.

Virtual screening: In the present work we have carried out structure based virtual screening where in the molecules from the focused library after ligand preparation were passed through dock score based filters. The flow chart for virtual screening is presented in Fig. 8.

In Virtual screening exercise we employed different docking protocols to identify virtual hits. First filter is glide high throughput virtual screening (HTVS) docking which rapidly screens actives from a large database and relatively less accurate with processing time of $2 \mathrm{sec} / \mathrm{compound}$ (CPU time). Second filter being Glide standard precision (SP) docking that is more refined compared to HTVS docking mode and processing time is 10

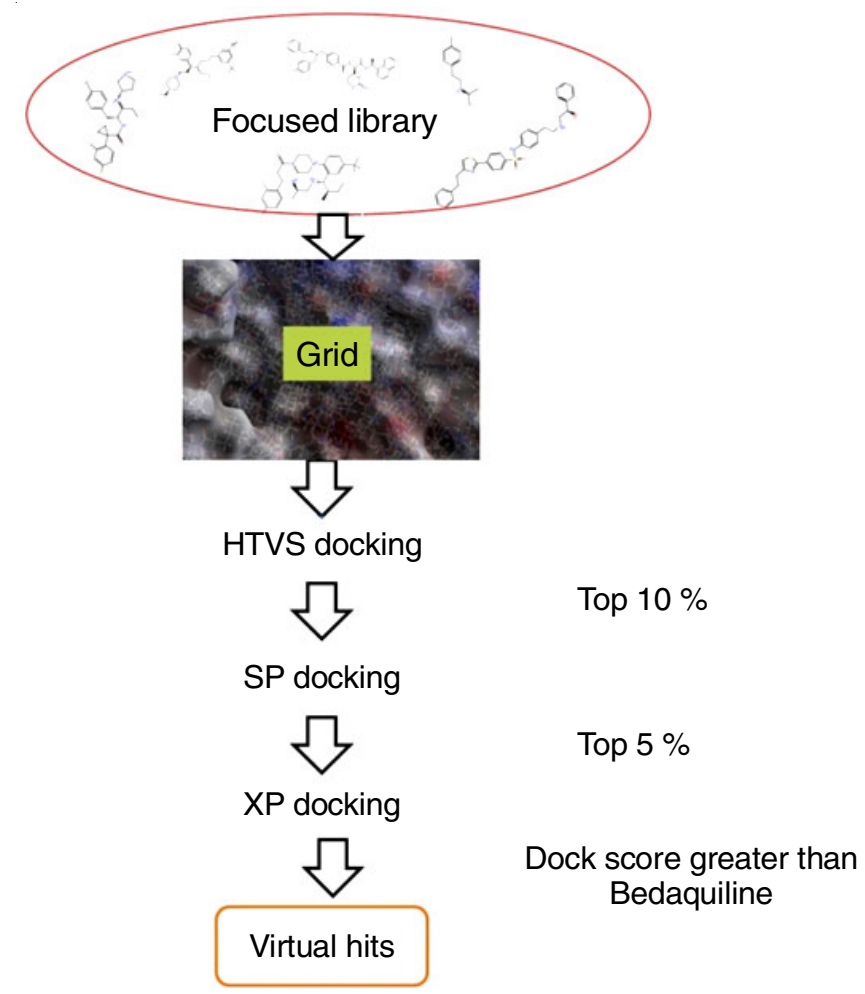

Fig. 8. Virtual screening work flow

sec/compound. Third filter is Glide XP docking performs more extensive sampling than SP and HTVS docking mode. Its advanced scoring function necessitates greater ligand-receptor complementarities to escape penalization. The processing speed in XP docking is $2 \mathrm{~min} /$ compound and has greater accuracy in spotting the actives in comparison to either SP/ HTVS mode of docking. 
Different docking methods like HTVS, SP and XP described earlier are rigid docking protocols where receptor is held rigid and ligand is flexible. In reality receptor is a dynamic entity and undergoes conformation changes during ligand binding. Induced fit docking (IFD) allows flexibility of residues at the ligand binding site and also uses a softened potential allowing close interaction of ligand with the binding site. Induced fit docking greatly reduces false positives obtained through a virtual screening exercise and binding affinity estimate of the ligand-receptor complex can be obtained from induced fit dock score.

ADME prediction for virtual hits: ADME (absorption, distribution, metabolism and excretion) properties of a compound are very critical in determining its druggability. QikProp module of schrödinger suite was used to predict the ADME properties of the virtual hits. QikProp prediction program predicts various pharmaceutically relevant physicobiological descriptors for a molecule and compares these parameters against $95 \%$ of the known drug candidates. This information gives a qualitative picture of molecules in question with respect to their drug-likeliness.

\section{RESULTS AND DISCUSSION}

Molecular docking of bedaquiline and its stereoisomers: Bedaquiline and its stereoisomers after ligand preparation were docked into the grid generated around glu-61. The results of
XP docking are shown in Fig. 9 and details summarized in Table-2.

The docking results (Table-2) show a good agreement with the experimental activity of the bedaquiline and its stereoisomers. This positive corelation fortifies the reliability of XP docking in finding molecules that can bind effectively to MTB $\mathrm{F}_{1} \mathrm{~F}_{0}$ ATPase.

Results of virtual screening: A total volume of 91,638 molecules were loaded into virtual screening workflow of Schrödinger suite. Ligprep module generated 2,16,318 conformers in total and 21,425 entries made out of HTVS docking filter. These output molecules dwindled down to 4,834 after passing through SP docking filter. These doubly filtered molecules on Glide XP docking yielded four molecules which showed higher XP dock score compared to bedaquiline $(-9.38 \mathrm{Kcal} / \mathrm{mol})$. The structures of the virtual hits are shown in the Fig. 10. Physico-chemical descriptors of virtual hits are shown in Table-3.

One glaring structural aspect in atleast three out of four output molecules is a piperazine moiety with a proximal hydroxy group, can been seen in the Fig. 10. (highlighted).

Summary of different docking parameters obtained from Glide XP, dockposes (Fig. 11) and with a detailed hydrogen bond interaction profile has been presented in Tables 4 and 5 . Induced fit docking scores can be seen in the same table. (Bedaquiline showed IF dock score of -5.4 and is not indicated in Table-4).

TABLE-2

RESULTS OF XP DOCKING OF BEDAQUILINE AND ITS STEREOISOMERS

\begin{tabular}{cccccc}
\hline $\begin{array}{c}\text { Stereoisomer } \\
\text { configuration }\end{array}$ & $\begin{array}{c}\left(\mathrm{MIC}_{90}\right) \\
(\mu \mathrm{g} / \mathrm{mL})\end{array}$ & $\begin{array}{c}\text { XPdock score } \\
(\mathrm{Kcal} / \mathrm{mol})\end{array}$ & $\begin{array}{c}\text { Glide Ecoul } \\
(\mathrm{Kcal} / \mathrm{mol})\end{array}$ & $\begin{array}{c}\text { Glide Evdw } \\
(\mathrm{Kcal} / \mathrm{mol})\end{array}$ & $\begin{array}{c}\text { Glide energy } \\
(\mathrm{Kcal} / \mathrm{mol})\end{array}$ \\
\hline RS(BQ) & 0.07 & -9.38 & -11.80 & -52.30 & -64.10 \\
RR(SS) & 2.78 & -8.83 & -8.20 & -48.15 & -56.31 \\
SS(RR) & 2.78 & -9.12 & -11.38 & -50.70 & -61.20 \\
SR & 44.13 & -7.40 & -6.65 & -40.32 & -46.97 \\
\hline
\end{tabular}

BQ: bedaquiline; EvdW = lipophilic van der Waals energy; Ecoul = coloumb energy; Biological activity [Ref. 28]

TABLE-3

THE PHYSICO-CHEMICAL DESCRIPTORS OF THESE VIRTUAL HITS

\begin{tabular}{cccccccccc}
\hline S. No. & PCID & GMW & HBD & HBA & RB & Complexity & TPSA $\left(\mathrm{A}^{2}\right)$ & $\mathrm{xlog} \mathrm{p}$ & FC \\
\hline 1 & 123254118 & 453.97 & 1 & 4 & 9 & 650 & 58.3 & 6.1 & 0 \\
2 & 54289035 & 531.70 & 1 & 5 & 10 & 736 & 52.7 & 6.0 & 0 \\
3 & 73351228 & 522.69 & 1 & 5 & 10 & 745 & 53.0 & 6.5 & 0 \\
4 & 20079045 & 558.52 & 1 & 5 & 6 & 695 & 48.8 & 5.6 & 0
\end{tabular}

Legend: PCID: PubChem data base ID; GMW: Gram molecular weight; HBD: Hydrogen bond donors; HBA: Hydrogen bond acceptors; RB: Rotatable bonds; TPSA: Topological polar surface area; FC: Formal charge.
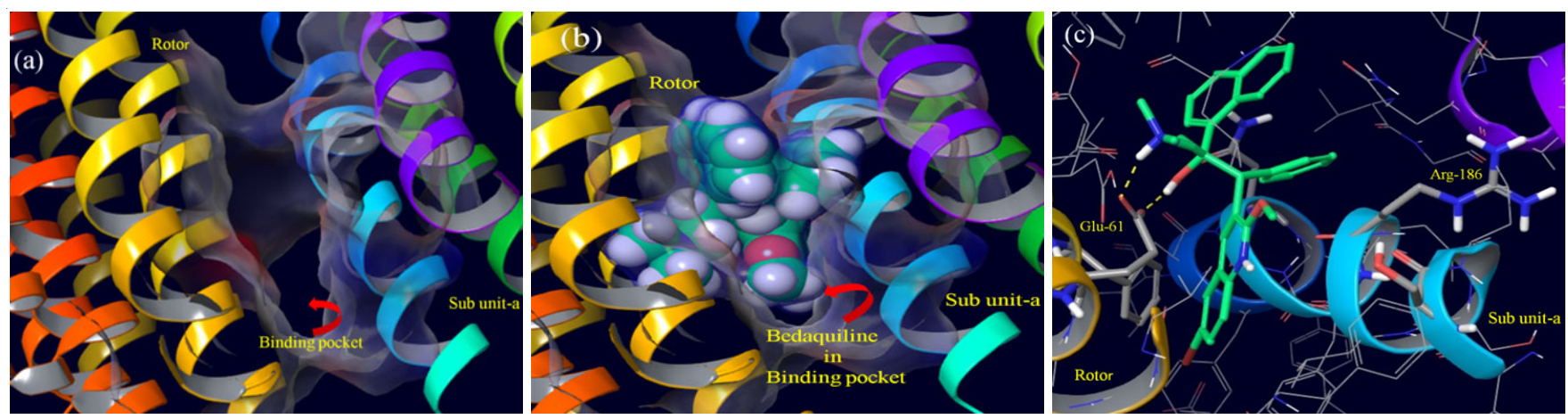

Fig. 9. (a) Binding cavity at the interface of $\mathrm{C}_{9}$ rotor and subunit-a (b) Bedaquiline (CPK model) docked in the binding cavity (c) Dock pose of bedaquiline at the interface of rotor and subunit-a 


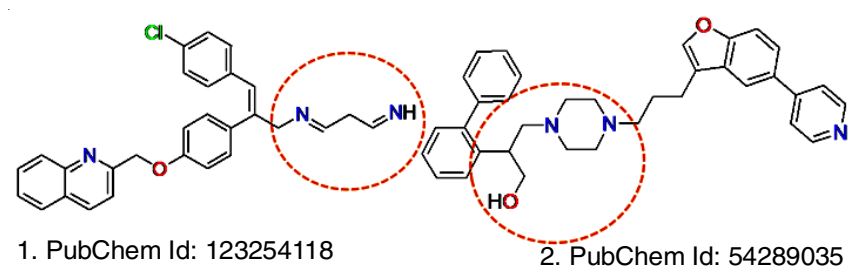

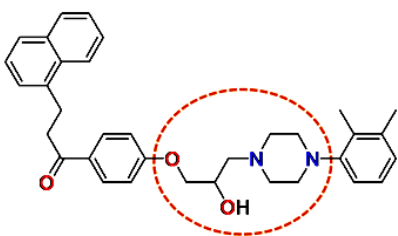

3. PubChem Id: 73351228

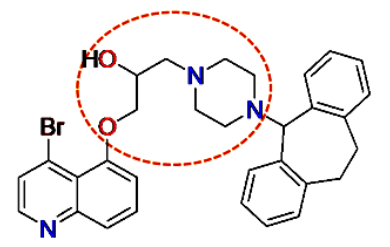

4. PubChem Id: 20079045

Fig. 10. Graphical depiction of 2D Structures of virtual hits
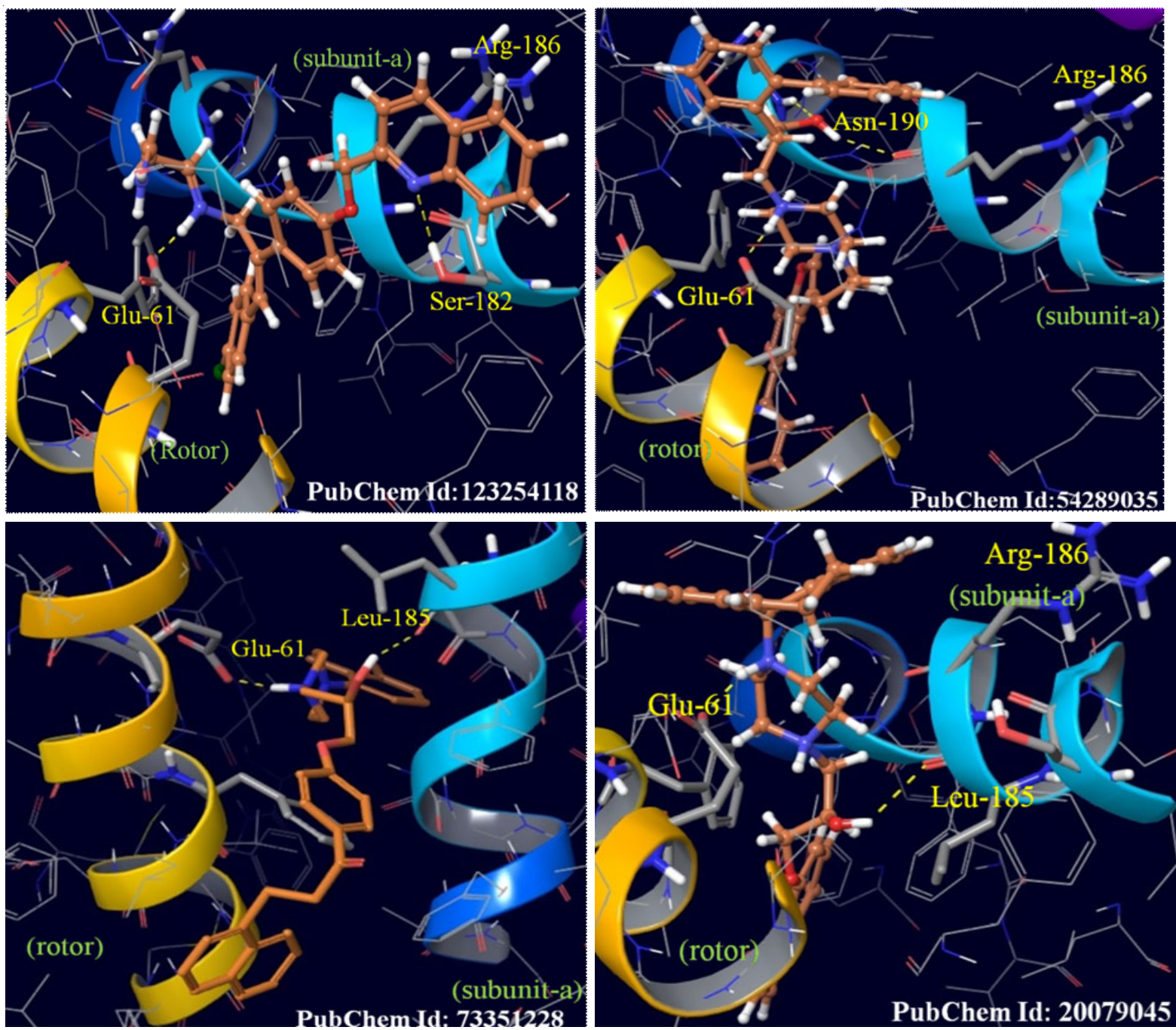

Fig. 11. Dock pose of virtual hits at the interface of subunit-a and rotor-c

TABLE-4

RESULT OF XP DOCKING OF THE VIRTUAL HITS

\begin{tabular}{cccccc}
\hline PC Id & $\begin{array}{c}\text { XPdock score } \\
(\mathrm{Kcal} / \mathrm{mol})\end{array}$ & $\begin{array}{c}\text { Glide Ecoul } \\
(\mathrm{Kcal} / \mathrm{mol})\end{array}$ & $\begin{array}{c}\text { Glide EvdW } \\
(\mathrm{Kcal} / \mathrm{mol})\end{array}$ & $\begin{array}{c}\text { Glide energy } \\
(\mathrm{Kcal} / \mathrm{mol})\end{array}$ & $\begin{array}{c}\text { IF Dock score } \\
(\mathrm{Kcal} / \mathrm{mol})\end{array}$ \\
\hline 123254118 & -12.40 & -21.00 & -47.37 & -68.31 & -8.26 \\
54289035 & -9.51 & -18.58 & -37.90 & -56.46 & -6.71 \\
73351228 & -10.65 & -8.95 & -44.01 & -53.04 & -5.65 \\
20079045 & -9.55 & -11.28 & -40.32 & -52.30 & -5.60 \\
\hline
\end{tabular}

EvdW = lipophilic van der Waals energy; Ecoul = coloumb energy 


\begin{tabular}{|c|c|c|c|c|c|}
\hline \multicolumn{6}{|c|}{$\begin{array}{c}\text { TABLE-5 } \\
\text { HYDROGEN BOND INTERACTION PROFILE OF VIRTUAL HITS (XP DOCKING) }\end{array}$} \\
\hline PubChem ID & No. of hydrogen bonds & Interacting residues & H-bond acceptor & H-bond donor & Distance $(\AA)$ \\
\hline 123254118 & 2 & Glu-61, Ser-182 & $\begin{array}{l}\text { Glu- } 61\left(\mathrm{O} \text { of } \mathrm{COO}^{-}\right) \\
\operatorname{Lig}(\mathrm{N})\end{array}$ & $\begin{array}{l}\operatorname{Lig}(=\mathrm{N}-\mathrm{H}) \\
\operatorname{Ser}(\mathrm{O}-\mathrm{H})\end{array}$ & $\begin{array}{l}1.5 \\
2.4\end{array}$ \\
\hline 54289035 & 3 & $\begin{array}{l}\text { Glu-61,Asn-190 } \\
\text { Arg186 }\end{array}$ & $\begin{array}{l}\text { Glu-61 }\left(\mathrm{O}^{-} \mathrm{COO}^{-}\right) \\
\text {Arg-186(O of C=O) } \\
\operatorname{Lig}(\mathrm{O})\end{array}$ & $\begin{array}{l}\text { Lig(N-H) } \\
\operatorname{Lig}(\mathrm{O}-\mathrm{H}) \\
\text { Asn-190(N-H) }\end{array}$ & $\begin{array}{l}1.6 \\
2.1 \\
2.2\end{array}$ \\
\hline 73351228 & 2 & Glu-61, Leu-185 & $\begin{array}{l}\text { Glu- } 61\left(\mathrm{O} \text { of } \mathrm{COO}^{-}\right) \\
\text {Leu- } 185(\mathrm{O} \text { of } \mathrm{C}=\mathrm{O})\end{array}$ & $\begin{array}{l}\operatorname{Lig}(\mathrm{N}-\mathrm{H}) \\
\operatorname{Lig}(\mathrm{O}-\mathrm{H})\end{array}$ & $\begin{array}{l}1.9 \\
2.0\end{array}$ \\
\hline 20079045 & 2 & Glu-61 & $\begin{array}{l}\text { Glu- } 61\left(\mathrm{O} \text { of } \mathrm{COO}^{-}\right) \\
\text {Leu- } 185(\mathrm{O} \text { of } \mathrm{C}=\mathrm{O})\end{array}$ & $\begin{array}{l}\operatorname{Lig}(\mathrm{N}-\mathrm{H}) \\
\operatorname{Lig}(\mathrm{O}-\mathrm{H})\end{array}$ & $\begin{array}{l}1.7 \\
2.4\end{array}$ \\
\hline
\end{tabular}

Lig stands for ligand and $\mathrm{C}=\mathrm{O}$ stands for carbonyl group of peptide linkage.

\begin{tabular}{|c|c|c|c|c|c|c|}
\hline \multicolumn{7}{|c|}{$\begin{array}{c}\text { TABLE-6 } \\
\text { ADME PREDICTION FOR VIRTUAL HITS }\end{array}$} \\
\hline \multirow{2}{*}{ Compound $^{\mathrm{a}}$} & \multirow{2}{*}{ QPlogHERG $^{\mathrm{b}}$} & \multirow{2}{*}{$\mathrm{QPPCaco}^{\mathrm{c}}$} & \multirow{2}{*}{ QPlog $S^{d}$} & \multirow{2}{*}{$\% \mathrm{HOA}$} & \multicolumn{2}{|c|}{ Number of violations } \\
\hline & & & & & Lipinski's rule of five ${ }^{f}$ & Jorgensen's rule of three \\
\hline Bedaquiline & -6.8 & 1045 & -6.0 & 96.5 & 2 & 1 \\
\hline 123254118 & -7.9 & 1126 & $-8.1 *$ & 100 & 1 & 1 \\
\hline 54289035 & -9.6 & 153 & -5.5 & 75 & 2 & 1 \\
\hline 73351228 & -8.8 & 321 & $-7.7^{*}$ & 83 & 2 & 2 \\
\hline 20079045 & -8.8 & 170 & -5.4 & 72 & 2 & 1 \\
\hline \multicolumn{7}{|c|}{$\begin{array}{l}\text { a Virtual hits along with bedaquiline. } \\
{ }^{\mathrm{b}} \mathrm{QPlogHERG} \mathrm{K}^{+} \text {channel blockage: } \log \mathrm{IC}_{50} \text { (concern below }-5 \text { ). } \\
\text { 'Predicted Caco cell permeability in } \mathrm{nm} / \mathrm{s}(\text { acceptable range: }<25 \text { is poor and }>500 \text { is great). } \\
{ }^{\mathrm{d}} \mathrm{QPlogS} \text {, predicted aqueous solubility in mol/L (acceptable range: }-6.5 \text { to } 0.5 \text { ). } \\
\text { } \% \mathrm{HOA} \text { (percentage of human oral absorption) (acceptable range: }<25 \text { is poor and }>80 \% \text { is high. } \\
\text { }{ }^{\mathrm{f}} \text { Lipinski rule of 5: Maximum number of violation in } 95 \% \text { of drugs is } 4 \text {. } \\
\text { g Jorgensen rule of 3: Maximum number of violation in } 95 \% \text { of drugs is } 3 \text {. }\end{array}$} \\
\hline
\end{tabular}

allows designing less lipophilic compounds and expands scope for designing new inhibitors against $\mathrm{MTB}_{1} \mathrm{~F}_{0}$ ATP synthase with better pharmacokinetic properties.

\section{Conclusion}

With a systematic integration of homology modeling and virtual screening tools with multiple filters, an attempt has been made to find molecules that can effectively inhibit MTB $\mathrm{F}_{1} \mathrm{~F}_{0}$ ATPase. In this quest, we obtained four virtual hits that fared better than bedaquiline in terms of their binding affinity. Some distinct features of these virtual hits that allow key interaction with glu-61 are shown in Fig. 12.

In summary we suggest that designing of novel MTB $\mathrm{F}_{1} \mathrm{~F}_{0}$ ATP synthase inhibitors with diverse scaffolds that share a close resemblance to the physical descriptors of bedaquiline and incorporating structural features indicated (Fig. 12) could afford potent inhibitors against $\mathrm{MTBF}_{1} \mathrm{~F}_{0}$ ATP synthase.

As always any in silico finding need to be experimentally quantified and our findings does provide synthetic chemists, an insight into the structural aspects to be envisaged while designing novel MTB $\mathrm{F}_{1} \mathrm{~F}_{0}$ ATPase inhibitors.

\section{ACKNOWLEDGEMENTS}

One of the authors, RK is extremely thankful to University Grants Commission, New Delhi, India for providing fellowship to carry out the research work and Department of Chemistry, University College of Science, Osmania University, Hyderabad, India for providing platform to work. The authors also acknowledge Schrödinger Inc. for Glide software used to perform these studies.

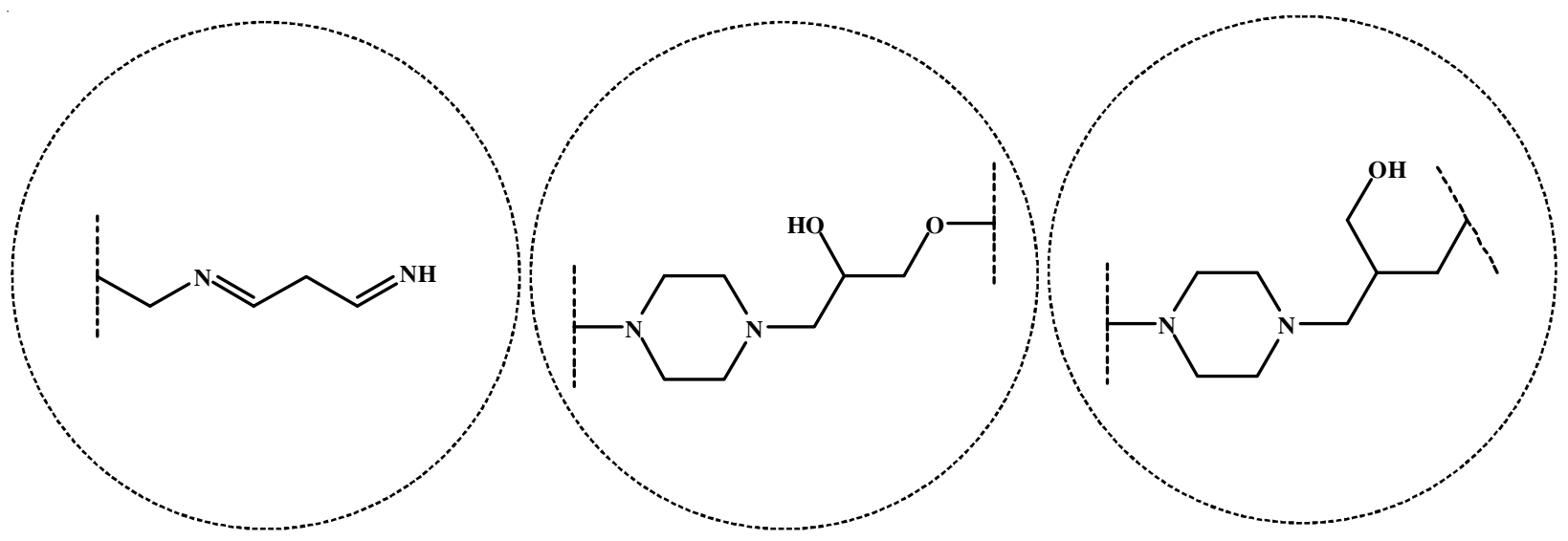

Fig. 12. Important structural features seen in four virtual hits 


\section{REFERENCES}

1. Global tuberculosis report (2016); http://apps.who.int/iris/bitstream/10665/250441/1/9789241565394eng.pdf?ua=1.

2. S.H. Kaufmann and A.J. McMichael, Nat. Med., 11(4s), S33 (2005); https://doi.org/10.1038/nm1221.

3. M. Klopper, R. Warren, C. Hayes, N. Gey van Pittius, E. Streicher, B. Müller, F.A. Sirgel, M. Chabula-Nxiweni, E. Hoosain, G. Coetzee, P. David van Helden, T.C. Victor and A.P. Trollip, Emerg. Infect. Dis., 19, 449 (2013); https://doi.org/10.3201/eid1903.120246.

4. N.S. Shah, A. Wright, G.-H. Bai, L. Barrera, F. Boulahbal, N. MartínCasabona, F. Drobniewski, C. Gilpin, M. Havelková, R. Lepe, R. Lumb, B. Metchock, F. Portaels, M.F. Rodrigues, S. Rüsch-Gerdes, A. Van Deun, V. Vincent, K. Laserson, C. Wells and J.P. Cegielski, Emerg. Infect. Dis., 13, 380 (2007); https://doi.org/10.3201/eid1303.061400.

5. Y. Zhang, K. Post-Martens and S. Denkin, Drug Discov. Today, 11, 21 (2006); https://doi.org/10.1016/S1359-6446(05)03626-3.

6. S. Anishetty, M. Pulimi and G. Pennathur, Comput. Biol. Chem., 29, 368 (2005);

https://doi.org/10.1016/j.compbiolchem.2005.07.001.

7. Sridhar, P. Dash and K. Guruprasad, Gene, 579, 69 (2016); https://doi.org/10.1016/j.gene.2015.12.054.

8. A.C. Haagsma, I. Podasca, A. Koul, K. Andries, J. Guillemont, H. Lill and D. Bald, PLoS One, 6, e23575 (2011); https://doi.org/10.1371/journal.pone.0023575.

9. D. Bald, C. Villellas, P. Lu and A. Koul, MBio, 8, e00272 (2017); https://doi.org/10.1128/mBio.00272-17.

10. K. Andries, P. Verhasselt, J. Guillemont, H.W. Göhlmann, J.M. Neefs, H. Winkler, J. van Gestel, P. Timmerman, M. Zhu, E. Lee, P. Williams, D. de Chaffoy, E. Huitric, S. Hoffner, E. Cambau, C. Truffot-Pernot, N. Lounis and V. Jarlier, Science, 307, 223 (2005); https://doi.org/10.1126/science.1106753.

11. N. Lounis, J. Guillemont, N. Veziris, A. Koul, V. Jarlier and K. Andries, Med. Mal. Infect., 40, 383 (2010); https://doi.org/10.1016/j.medmal.2009.09.007.

12. A.C. Haagsma, R. Abdillahi-Ibrahim, M.J. Wagner, K. Krab, K. Vergauwen, J. Guillemont, K. Andries, H. Lill, A. Koul and D. Bald, Antimicrob. Agents Chemother., 531290 (2009); https://doi.org/10.1128/AAC.01393-08.

13. World Health Organization. The Use of Bedaquiline in the Treatment of Multidrug-resistant Tuberculosis. Interim Policy Guidance (WHO/ HTM/TB/2013.6), Geneva, Switzerland, November (2013).

14. E. Cox and K. Laessig, N. Engl. J. Med., 371, 689 (2014); https://doi.org/10.1056/NEJMp1314385.

15. L. Preiss, J.D. Langer, O. Yildiz, L. Eckhardt-Strelau, J.E.G. Guillemont, A. Koul and T. Meier, Sci. Adv., 1, 106 (2015); https://doi.org/10.1126/sciadv.1500106.

16. R.S. Upadhayaya, J.K. Vandavasi, N.R. Vasireddy, V. Sharma, S.S. Dixit and J. Chattopadhyaya, Bioorg. Med. Chem., 17, 2830 (2009); https://doi.org/10.1016/j.bmc.2009.02.026.

17. R.S. Upadhayaya, J.K. Vandavasi, R.A. Kardile, S.V. Lahore, S.S. Dixit, H.S. Deokar, P.D. Shinde, M.P. Sarmah and J. Chattopadhyaya, Eur. J. Med. Chem., 45, 1854 (2010); https://doi.org/10.1016/j.ejmech.2010.01.024.
18. S. Singh, K.K. Roy, S.R. Khan, V.K. Kashyap, A. Sharma, S. Jaiswal, S.K. Sharma, M.Y. Krishnan, V. Chaturvedi, J. Lal, S. Sinha, A. Dasgupta, R. Srivastava and A.K. Saxena, Bioorg. Med. Chem., 23, 742 (2015); https://doi.org/10.1016/j.bmc.2014.12.060.

19. S.J. Tantry, V. Shinde, G. Balakrishnan, S.D. Markad, A.K. Gupta, J. Bhat, A. Narayan, A. Raichurkar, L.K. Jena, S. Sharma, N. Kumar, R. Nanduri, S. Bharath, J. Reddy, V. Panduga, K.R. Prabhakar, K. Kandaswamy, P. Kaur, N. Dinesh, S. Guptha, R. Saralaya, M. Panda, S. Rudrapatna, M. Mallya, H. Rubin, T. Yano, K. Mdluili, C.B. Cooper, V. Balasubramanian, V.K. Sambandamurthy, V. Ramachandran, R. Shandil, S. Kavanagh, S. Narayanan, P. Iyer, K. Mukherjee, V.P. Hosagrahara, S. Solapure, S. Hameed and S. Ravishankar, MedChemComm, 7, 1022 (2016); https://doi.org/10.1039/C5MD00589B.

20. S.F. Altschul, T.L. Madden, A.A. Schaffer, J. Zhang and Z. Zhang, Nucleic Acids Res., 25, 3389 (1997); https://doi.org/10.1093/nar/25.17.3389.

21. M. Biasini, S. Bienert, A. Waterhouse, K. Arnold, G. Studer, T. Schmidt, F. Kiefer, T.G. Cassarino, M. Bertoni, L. Bordoli and T. Schwede, Nucleic Acids Res., 42, W252 (2014); https://doi.org/10.1093/nar/gku340.

22. L. Bordoli, F. Kiefer, K. Arnold, P. Benkert and J. Battey and T. Schwede, Nat Protoc., 4, 1 (2009); https://doi.org/10.1038/nprot.2008.197.

23. K. Arnold, L. Bordoli and J. Kopp and T. Schwede, Bioinformatics., 22 195 (2006); https://doi.org/10.1093/bioinformatics/bti770.

24. S.C. Lovell, I.W. Davis, W.B. Arendall III, P.I.W. de Bakker, J.M. Word, M.G. Prisant, J.S. Richardson and D.C. Richardson, Proteins, 50, 437 (2003); https://doi.org/10.1002/prot.10286.

25. D. Kozma, I. Simon and G.E. Tusnády, Nucleic Acids Res., 41(D1), D524 (2012); https://doi.org/10.1093/nar/gks1169.

26. G. Studer, M. Biasini and T. Schwede, Bioinformatics, 30, i505 (2014); https://doi.org/10.1093/bioinformatics/btu457.

27. Schrödinger, Suite 10.0, Schrödinger, LLC New York, NY (2009).

28. M.R. de Jonge, L.H.M. Koymans, J.E.G. Guillemont, A. Koul and K. Andries, PROTEINS: Struct. Func. and Bioinf, 67, 971 (2007); https://doi.org/10.1002/prot.21376.

29. S. Kim, P.A. Thiessen, E.E. Bolton, J. Chen, G. Fu, A. Gindulyte, L. Han, J. He, S. He, B.A. Shoemaker, J. Wang, B. Yu, J. Zhang and S.H. Bryant, Nucleic Acids Res., 44, D1202 (2016); https://doi.org/10.1093/nar/gkv951.

30. W. Tong, W.J. Welsh, L. Shi, H. Fang and R. Perkins, Environ. Toxicol. Chem., 22, 1680 (2003); https://doi.org/10.1897/01-198.

31. R. Guha, Methods Mol. Biol., 993, 81 (2013); https://doi.org/10.1007/978-1-62703-342-8_6.

32. A.S.T. Tong, P.J. Choi, A. Blaser, H.S. Sutherland, J. Guillemont, S.K.Y. Tsang, M. Motte, C.B. Cooper, K. Andries, W. Van den Broeck, A.M. Upton, S.G. Franzblau, W.A. Denny, B.D. Palmer and D. Conole, ACS Med. Chem. Lett., 8, 1019 (2017); https://doi.org/10.1021/acsmedchemlett.7b00196. 